\title{
A Brief Review on Biting/Stinging of Animals and Its Risk of Infection
}

\author{
Rouhullah Dehghani ${ }^{1}$, Hamid Kassiri ${ }^{2,{ }^{*}}$ and Mousa Dehghani ${ }^{3}$ \\ ${ }^{1}$ Social Determinants of Health Research Center, Department of Environment Health, Kashan University of Medical Sciences, Kashan, Iran \\ ${ }^{2}$ Department of Medical Entomology and Vector Control, Faculty of Health, Ahvaz Jundishapur University of Medical Sciences, Ahvaz, Iran \\ ${ }^{3}$ Department of Environmental Science, Faculty of Natural Resources, Isfahan University of Technology, Isfahan, Iran \\ "Corresponding author: Department of Medical Entomology and Vector Control, Faculty of Health, Ahvaz Jundishapur University of Medical Sciences, Ahvaz, Iran. Email: \\ hamid.kassiri@yahoo.com
}

Received 2019 August 26; Revised 2020 January 15; Accepted 2020 February 01.

Keywords: Spider, Bite, Sting, Scorpion, Velvet Ant, Snake

\section{Dear Editor,}

Bites of animals and their problems in humans and livestock cause significant health and economic losses in countries (1). Bites and stings of animals usually occur in the defense of their survival. In other cases, biting and stinging may be done in an attempt to obtain food (2). The cases of humans bitten by animals, in particular during poisonous occasions, are often due to animals' sense of fear and risk caused by the known instinctive behavior of most animals, including snakes and scorpions (Figure 1) (3, 4).

Bites of animals, in addition to local injury, will cause the risk of poisoning and infection. Considering the importance of local or systemic infections due to bites and stinging of some venomous animals, it is necessary to raise the awareness of physicians and medical staff about this issue, therefore, this article was presented.

Most snakes cause infection due to oral microbial flora (5-7). Snake bites are especially important in the rural areas of tropical and subtropical countries located in Africa, Asia, Latin America, and the Pacific. It is estimated that at least 421000 bites and 20000 deaths worldwide occur every year due to snake bites (8). More than 10 million people are being treated annually in different regions around the world due to bites. Animal bites and diseases caused by it are of the economic health problems in Iran, and almost all regions have this problem. According to the statistics published by the Center for Disease Management, the distribution of animal bite cases in the country has been reported to be 100 - 450 per 100000 people (9). On this basis, it can be estimated that there are 800000 to 3600000 animal bites in Iran, annually. Bites of animals can cause local to systemic damages. In some cases, secondary infections have been observed due to venomous and non- venomous snake bites. Wound and necrosis is created at the site of the bite of some poisonous snakes, especially vipers, which increases the risk of secondary fungal and bacterial infections $(10,11)$. The snakes' mouth flora varies between different species as well as different geographic regions. Even some researchers find seasonal changes effective in snakes' mouth flora $(12,13)$. Bacterial species have been widely identified from the mouth of snakes, the most important of which are Pseudomonas aeromonas, staphylococcus aureus, Escherichia coli, Proteus, Clostridium, Enterococcus and coagulase-negative Staphylococcus, Acinetobacter, klebsiella, and Shigella $(14,15)$.

Arachnida is one of the most important poisonous arthropods, among which scorpions and spiders are more important than others (Figure 2) (16). Some Arachnida species, such as Solpugids are hunter beasts larger than spiders, but they have no poison unlike spiders. They cause fear because of aggressive behavior. The Solpugids bite to defend themselves, which may lead to wounds. The contamination of these wounds with soil microbial agents may cause infection (17). Scorpions cause stings more than other poisonous animals in Iran; they are more abundant in tropical areas. Due to the type of climate, Iran is very rich in scorpions, so far, scorpions from three families have been reported in Iran. Iran is among the countries where many species of scorpions, especially dangerous ones, have been reported (18). A scorpion sting causes infection as well as poisoning. Topical complications, most commonly cellulitis, sepsis, abscess, and systemic such as infection and endocarditis have been reported (19-21).

A large part of the bites is due to poisonous animals that are usually more considered in the therapeutic area because of fear of the dangers of poison. In the problem of animal bites, in addition to the effects of poison and local 

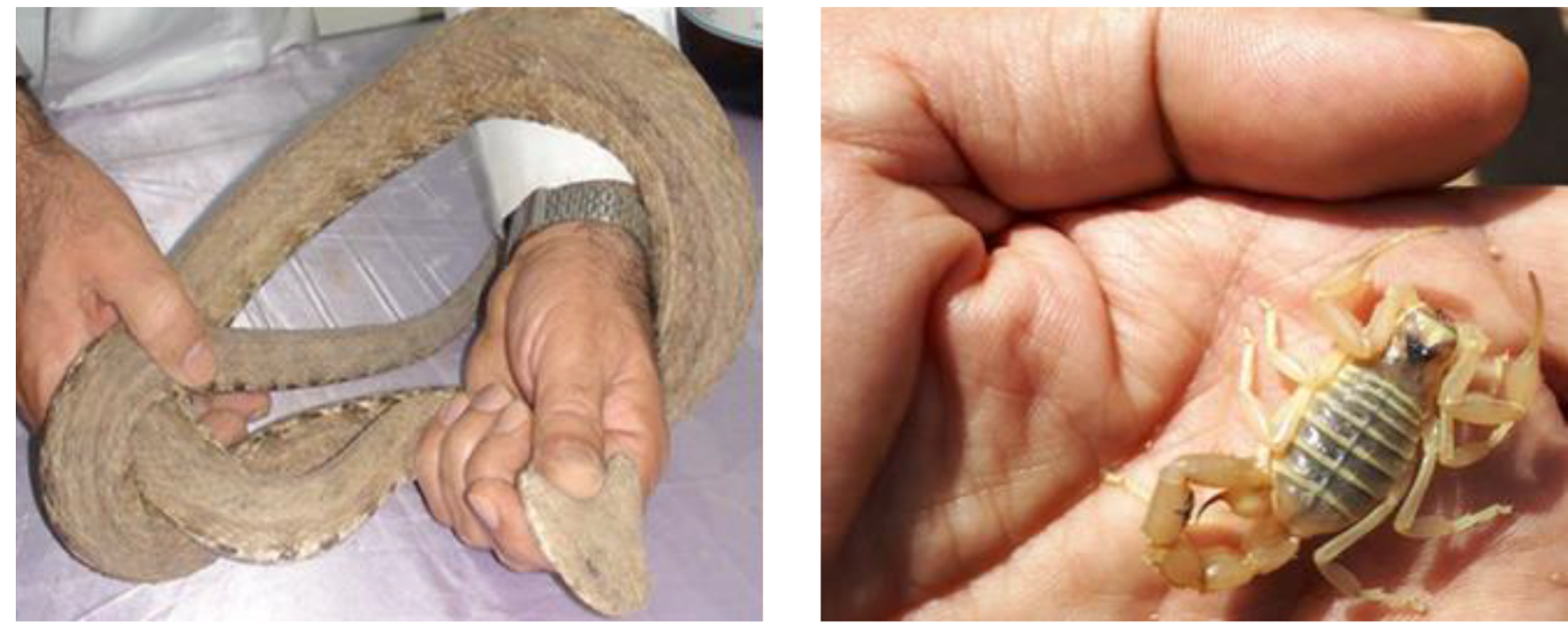

Figure 1. Left, Macrovipera lebetina; Right, Odontobuthus doriae (photoes prepared by R. Dehghani)

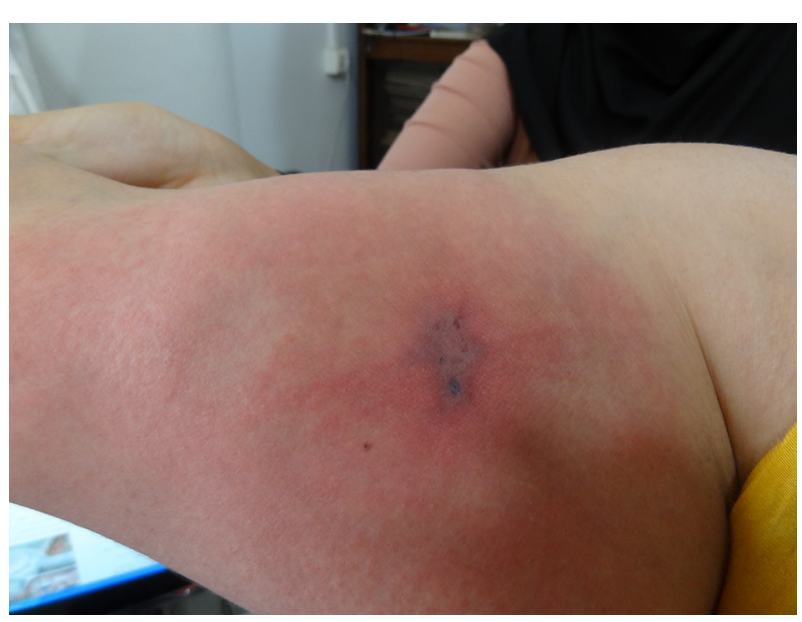

Figure 2. Erythema and necrosis after brown widow spider bite in the medial elbow (photo prepared by R. Dehghani)

injuries such as wounds and trauma, other aspects must be considered; one of these aspects is the risk of infection, which is a major issue for people with immune system deficiency or those taking immunosuppressive drugs $(22,23)$. Therefore, physicians and the treatment team should be aware of the possibility of infection in these patients when faced with bites and stings of poisonous animals. Given the high animal bite rate in Iran, all aspects of this inclusive problem, including the effects of poison, the risk of infection, and the prevention and reduction of animal stings and bites, should be addressed through the implementation of a coherent national and regional program (24-26).

In Iran, biting and stinging of venomous animals such as Viperidae family snakes, brown widow spider, and Hemiscorpius leptrus scorpion, can cause tissue necrosis, which is due to the fact that they have cytotoxic and hemolytic agents in their venom, and may result in local or systemic infection. Therefore, physicians and medical staff have to have sufficient knowledge of the animal venom properties in their own workplace.

\section{Footnotes}

Authors' Contribution: Rouhullah Dehghani, Hamid Kassiri, and Mousa Dehghani developed the original idea and the protocol, abstracted and analyzed data, and wrote the manuscript.

Conflict of Interests: No conflict of interest is reported. Funding/Support: None is declared by the authors.

\section{References}

1. Kassiri H, Lotfi M, Ebrahimi A. Epidemiological and demographic study of acute animal biting in Abdanan County, Ilam Province, Western Iran.J Acute Dis. 2017;6(6):272. doi: 10.4103/2221-6189.221292.

2. Dehghani R, Kassiri H, Gharali B, Hoseindoost G, Chimehi E, Takhtfiroozeh S, et al. Introducing of a new sting agent of velvet ant dentilla sp. (hymenoptera: Mutillidae) in Kashan, Centerl of Iran (2014 - 2015). Arch Clin Infect Dis. 2018;13(6). doi: 10.5812/archcid.60553.

3. Dehghani R, Sharif A, Madani M, Kashani HH, Sharif MR. Factors influencing animal bites in Iran: A descriptive study. Osong Public Health Res Perspect. 2016;7(4):273-7. doi: 10.1016/j.phrp.2016.06.004. [PubMed: 27635378]. [PubMed Central: PMC5014749].

4. Dehghani R, Rastegar pouyani N, Dadpour B, Keyler D, Panjehshahi M, Jazayeri M, et al.A survey on non-venomous snakes in Kashan (Central Iran). J Biol Today's World. 2016;5(4). doi: 10.15412/j.jbtw.01050402. 
5. Terry P, Mackway-Jones K. Towards evidence based emergency medicine: best BETs from the Manchester Royal Infirmary. Antibiotics in non-venomous snakebite. Emerg Med J. 2002;19(2):142. doi: 10.1136/emj.19.2.142. [PubMed: 11904264]. [PubMed Central: PMC1725823].

6. Kassiri H. Incidence and epidemiological profile of snakebites and scorpion stings in Northern Khuzestan Province, Southwestern Iran: A descriptive, analytical study. Asian J Pharm. 2018;12(3).

7. Kassiri H, Dehghani R, Kamiabi F, Hashemi A, Mohammadza N, Gharagazlo F. A study on litter size and abundance of newborns in several Iranian scorpion species. J Entomol. 2018;15(3):155-60. doi: 10.3923/je.2018.155.160.

8. Kasturiratne A, Wickremasinghe AR, de Silva N, Gunawardena NK, Pathmeswaran A, Premaratna R, et al. The global burden of snakebite: A literature analysis and modelling based on regional estimates of envenoming and deaths. PLoS Med. 2008;5(11). e218. doi: 10.1371/journal.pmed.0050218. [PubMed:18986210]. [PubMed Central: PMC2577696].

9. Kassiri H, Ebrahimi A, Lotfi M. Animal bites: Epidemiological considerations in the east of Ahvaz County, Southwestern Iran (2011 - 2013). Arch Clin Infect Dis. 2018;13(5). doi: 10.5812/archcid.62384.

10. Dehghani R, Sharif MR, Moniri R, Sharif A, Kashani HH. The identification of bacterial flora in oral cavity of snakes. Comp Clin Pathol. 2015;25(2):279-83. doi: 10.1007/s00580-015-2178-9.

11. Dehghani R, Sharif A, Assadi MA, Haddad Kashani H, Sharif MR. Fungal flora in the mouth of venomous and non-venomous snakes. Comp Clin Pathol. 2016;25(6):1207-11. doi:10.1007/s00580-016-2330-1.

12. Thomas N, Brook I. Animal bite-associated infections: Microbiology and treatment. Expert Rev Anti Infect Ther. 2011;9(2):215-26. doi: 10.1586/eri.10.162. [PubMed: 21342069].

13. Panda SK, Padhi L, Sahoo G. Oral bacterial flora of Indian cobra (Naja naja) and their antibiotic susceptibilities. Heliyon. 2018;4(12). e01008. doi: 10.1016/j.heliyon.2018.e01008. [PubMed: 30582036]. [PubMed Central: PMC6298943].

14. Theakston RDG, Phillips RE, Looareesuwan S, Echeverria P, Makin T, Warrell DA. Bacteriological studies of the venom and mouth cavities of wild Malayan pit vipers (Calloselasma rhodostoma) in southern Thailand. Trans Royal Soc Trop Med Hygiene. 1990;84(6):875-9. doi: 10.1016/0035-9203(90)90112-r.

15. Fonseca MG, Moreira WMQ, Cunha KC, Ribeiro A, Almeida MTG. Oral microbiota of Brazilian captive snakes. J Venom Anim Toxins.
2009;15(1):54-60. doi: 10.1590/s1678-91992009000100006.

16. Sanaei-Zadeh H. Spider bite in Iran. Electron Physician. 2017;9(7):47037. doi: 10.19082/4703. [PubMed: 28894524]. [PubMed Central: PMC5586982].

17. Dehghani R. Solpugidophobia in Iran: Real or illusion. J Biol Today's World. 2017;6(3). doi: 10.15412/j.jbtw.01060302.

18. Dehghani R, Kassiri H, Mohammadzadeh N. Comparison of various methods of collecting scorpions (arachnida, scorpiones) in Khuzestan Province, Southwestern Iran. Arch Clin Infect Dis. 2019;14(4). doi: 10.5812/archcid.84452.

19. Pourahmad M, Sepidkar A, Farokhnia MH, Tadayon SM, Salehi H, Zabetian $\mathrm{H}$. Mucormycosis after scorpion sting: Case report. Mycoses. 2013;56(5):589-91. doi: 10.1111/myc.12066. [PubMed: 23496060].

20. Trisolini R, Paioli D, Patelli M, Cancellieri A, Squintani L. Bronchoalveolar lavage: Intact granulomas in Mycobacterium avium pulmonary infection. Acta Cytol. 2008;52(2):263-4. doi: 10.1159/000325497. [PubMed: 18500009].

21. Wheatley G3, Wait MA, Jessen ME. Infective endocarditis associated with a scorpion sting. Ann Thorac Surg. 2005;80(4):1489-90. doi: 10.1016/j.athoracsur.2004.04.004. [PubMed: 16181896].

22. Langley R, Mack K, Haileyesus T, Proescholdbell S, Annest JL. National estimates of noncanine bite and sting injuries treated in US Hospital Emergency Departments, 2001-2010. Wilderness Environ Med. 2014;25(1):14-23. doi: 10.1016/j.wem.2013.08.007. [PubMed: 24433776]. [PubMed Central: PMC4608679].

23. Hsiao M, Yang M, Yan S, Yang C, Chou C, Chang C, et al. Environmental factors associated with the prevalence of animal bites or stings in patients admitted to an emergency department.JAcute Med. 2012;2(4):95-102. doi:10.1016/j.jacme.2012.09.002.

24. Jalali A, Rahim F. Epidemiological review of scorpion envenomation in Iran. Iran J Pharm Res. 2014;13(3):743.

25. Monzavi SM, Afshari R, Khoshdel AR, Mahmoudi M, Salarian AA, Samieimanesh F, et al. Analysis of effectiveness of Iranian snake antivenom on Viper venom induced effects including analysis of immunologic biomarkers in the Echis carinatus sochureki envenomed victims. Toxicon. 2019;158:38-46. doi: 10.1016/j.toxicon.2018.11.293. [PubMed: 30452924].

26. Dehghani R, Fathi B, Shahi MP, Jazayeri M. Ten years of snakebites in Iran. Toxicon. 2014;90:291-8. doi: 10.1016/j.toxicon.2014.08.063. [PubMed: 25193748]. 